\title{
ESTUDO DA PERCEPÇÃO AMBIENTAL SOBRE ARBORIZAÇÃO URBANA NO BAIRRO FONTE BOA, TEFÉ-AMAZONAS, BRASIL
}

\author{
STUDY OF ENVIRONMENTAL PERCEPTION ABOUT URBAN TREE PLANTIG IN \\ FONTE BOA NEIGHBORHOOD, TEFÉ-AMAZONAS, BRAZIL
}

\author{
Lizane Paula Santos de Souza Maia ${ }^{1}$, Eudivane Dutra de Oliveira², Miely Oliveira dos Santos ${ }^{3}$, \\ Wilsandrei Cella ${ }^{4}$
}

\section{RESUMO}

A arborização urbana proporciona vários benefícios que são decisivos na qualidade de vida da população. No entanto, caso essa atividade não seja realizada de forma planejada, pode causar diversos entraves para a sociedade. Os estudos sobre a percepção ambiental sobre a arborização urbana são indispensáveis para a compreensão da relação do homem com o ambiente no qual está inserido. Objetivou-se avaliar o nível de percepção dos moradores do bairro Fonte Boa no município de Tefé-Amazonas, sobre a sua arborização. A metodologia utilizada fundamentou-se em entrevistas com questionário contendo perguntas objetivas e abertas, o qual foi realizado de forma aleatória nas 12 ruas do referido bairro, totalizando 120 entrevistas. Os resultados indicaram que $77,5 \%$ dos entrevistados não possuem conhecimentos aprofundados do conceito de "arborização urbana". Todavia, reconhecem suas vantagens, no qual $42,1 \%$ citaram principalmente a sombra como benefício. Em relação as desvantagens, 59,9\% notam pontos negativos. Referente ao responsável pela arborização urbana, $51,7 \%$ dos participantes atribuíram a responsabilidade aos próprios moradores, o que pode ser um fato negativo. Conclui-se que há necessidade em elaborar e executar programas de educação ambiental, bem como implementar projeto de arborização local.

Palavras-chave: Árvores; Educação ambiental; Amazônia.

\section{ABSTRACT}

The urban trees provide several benefits that are decisive in the quality of life of the population. However, if this activity is not accomplished in the right way, it can cause several problems to the society. The studies of the environmental perception about urban trees are indispensable for understanding the relation of man with the environment. The aim of this study was to evaluate the level of environmental perception of residents of the district Fonte Boa, about its tree planting. The used methodology was based on interviews with questionnaire containing objective and opened questions, which was accomplish randomly in 12 streets of referred district, totalizing 120 interviews. The results indicated that $77,5 \%$ of the people interviewed does not have knowledge about "urban trees". However, they recognize their advantages, of which $42,1 \%$ cited the shadow as the main benefit. In relation to disadvantages, $59,9 \%$ notice negative points, on the other hand, $40,1 \%$ said not observing any disadvantage. Regarding the responsibility for the urban trees, $51,7 \%$ of the participants attributed it to the Inhabitants. It is possible to conclude that there is a need to create environmental education programs, as well as, the elaboration and implementation of projects of local afforestation.

Keywords: Trees; Environmental education; Amazonia.

Recebido em 11.12.2016 e aceito em 24.03.2017

1 Tecnóloga em Gestão Ambiental. Universidade do Estado do Amazonas - UEA. Tefé/AM. Email: lizanepaulass@gmail.com

2 Tecnóloga em Gestão Ambiental. Universidade do Estado do Amazonas - UEA. Tefé/AM. Email: eudivaned@gmail.com

3 Tecnóloga em Gestão Ambiental. Universidade do Estado do Amazonas - UEA. Tefé/AM. Email: mielly.oliveira@gmail.com

4 Biólogo. Mestre em Ciências da Saúde. Especialista em Gestão Ambiental. Docente do Curso de Ciências Biológicas da Universidade do Estado do Amazonas - UEA. Tefé/AM. Email: wcella@uea.edu.br 


\section{INTRODUÇÃO}

A preocupação com a problemática ambiental nos últimos anos tem alcançado cada vez mais sua devida importância na sociedade. Os assuntos referentes à crise ambiental têm crescido de forma significativa (WALDMAN, 2011). Atualmente, grande parte da população passou a se concentrar nas áreas urbanas, muitas vezes em busca de melhores oportunidades, e essa ocupação dos espaços urbanos sem nenhum planejamento e de forma inapropriada tem ocasionado alterações na paisagem e no microclima resultando no desequilíbrio do meio ambiente (SILVA NETO; ALEIXO, 2014).

O processo de urbanização de forma desordenada tem por principal característica a retirada das áreas verdes para a ocupação dos espaços, e consequentemente, o aumento das áreas de edificações gerando impactos socioambientais ocasionando o desequilíbrio no meio ambiente (GOIS et al., 2012).

A arborização urbana é definida como um conjunto de vegetação arbórea, seja ela natural ou nativa, cultivada em áreas urbanas públicas e particulares (COSTA; BEZERRA; FREIRE, 2013). E tem sido pauta de várias discussões, pois pelos seus vários benefícios à sociedade, é vista como a principal ferramenta para reestabelecer o vínculo do homem com o ambiente natural, a qual é essencial para aquisição de uma melhor qualidade de vida e por amenizar os impactos negativos causados ao meio ambiente (FARIA; MONTEIRO; FISCH, 2007).

Neste contexto, é de vital importância para a população a presença de vegetação no espaço urbano, pois a mesma proporciona vários benefícios, tais como: bem estar ao ser humano, melhor efeito estético a cidade, sombreamento, redução da temperatura, abrigo para a fauna silvestre, liberação de oxigênio por meio do processo de fotossíntese e atuam na retenção do gás carbônico (QUADROS; FREIRE, 2009). Esses benefícios são decisivos para salubridade da população e do meio ambiente (COLETTO; MÜLLER; WOLSKI, 2008).

A arborização urbana é uma atividade que necessita de planejamento voltado para as necessidades de cada localidade, e é indispensável a realização da escolha dos espécimes, e de forma variada objetivando manter a biodiversidade das espécies. Para que a arborização urbana seja realizada com qualidade é necessária a atuação dos órgãos competentes responsáveis (PERIOTTO et al., 2016).

No entanto, caso a arborização não seja realizada de forma planejada pode acarretar em uma série de prejuízos a população, tais como: conflitos com a rede elétrica, degradação da pavimentação das ruas e calçadas e entupimento de calhas e entre outros (PAGLIARI; DORIGON, 2013). Sendo assim, os estudos sobre a percepção ambiental dos moradores em relação à arborização são essenciais para a compreensão a respeito da relação do homem e o 
meio ambiente, suas expectativas e insatisfações em relação ao ambiente no qual vive (VIANA et al., 2014).

A percepção ambiental é a forma como o ser humano entende o ambiente à sua volta, a partir de suas satisfações e insatisfações, compreendendo assim suas interações de forma que aprenda a respeitá-lo e a preservá-lo. As pesquisas sobre a percepção ambiental são de grande valia para investigar conhecimentos, crenças, opiniões e costumes que a população tem em relação ao local onde habita e o valor que é atribuído a este. Todo ser humano age de forma diferente em relação ao ambiente físico (COSTA; COLESANTI, 2011). Neste contexto, a percepção ambiental é um instrumento indispensável na defesa e gestão do ambiente, pois tem o intuído de aproximar o homem e o ambiente natural, visto que desperta responsabilidade e respeito por parte dos indivíduos em relação ao meio ambiente, garantido assim um futuro de mais qualidade de vida a todos (VILLAR et al., 2008).

Diante destes fatos, o presente estudo teve por objetivo avaliar o nível de percepção ambiental dos moradores do bairro de Fonte Boa, Tefé - AM em relação à arborização urbana e identificar seus pontos positivos e negativos, com o intuito de subsidiar informações acerca da arborização no município de modo a contribuir para elaboração de futuro plano de gestão de arborização urbana.

\section{MATERIAL E MÉTODOS}

\section{Descrição da área de estudo}

Este estudo foi desenvolvido no bairro Fonte Boa localizado no município de TeféAmazonas (Figuras $1 \mathrm{~A}$ ). O Município está situado à margem direita do Lago de Tefé. Área da unidade territorial 23.704,475 km², sua população é de 61.453 habitantes (IBGE, 2010). O mesmo faz limite com Alvarães, Maraã, Tapauá, Carauari e Coari, e destaca-se como polo regional estratégico que atende as demandas de cidades vizinhas (PORTO, 2011). A seleção do referido bairro justifica-se por ser uma amostra de conveniência, pois a região apresenta o mínimo de infraestrutura urbana e um perfil predominantemente residencial. (Figura 1 A). 


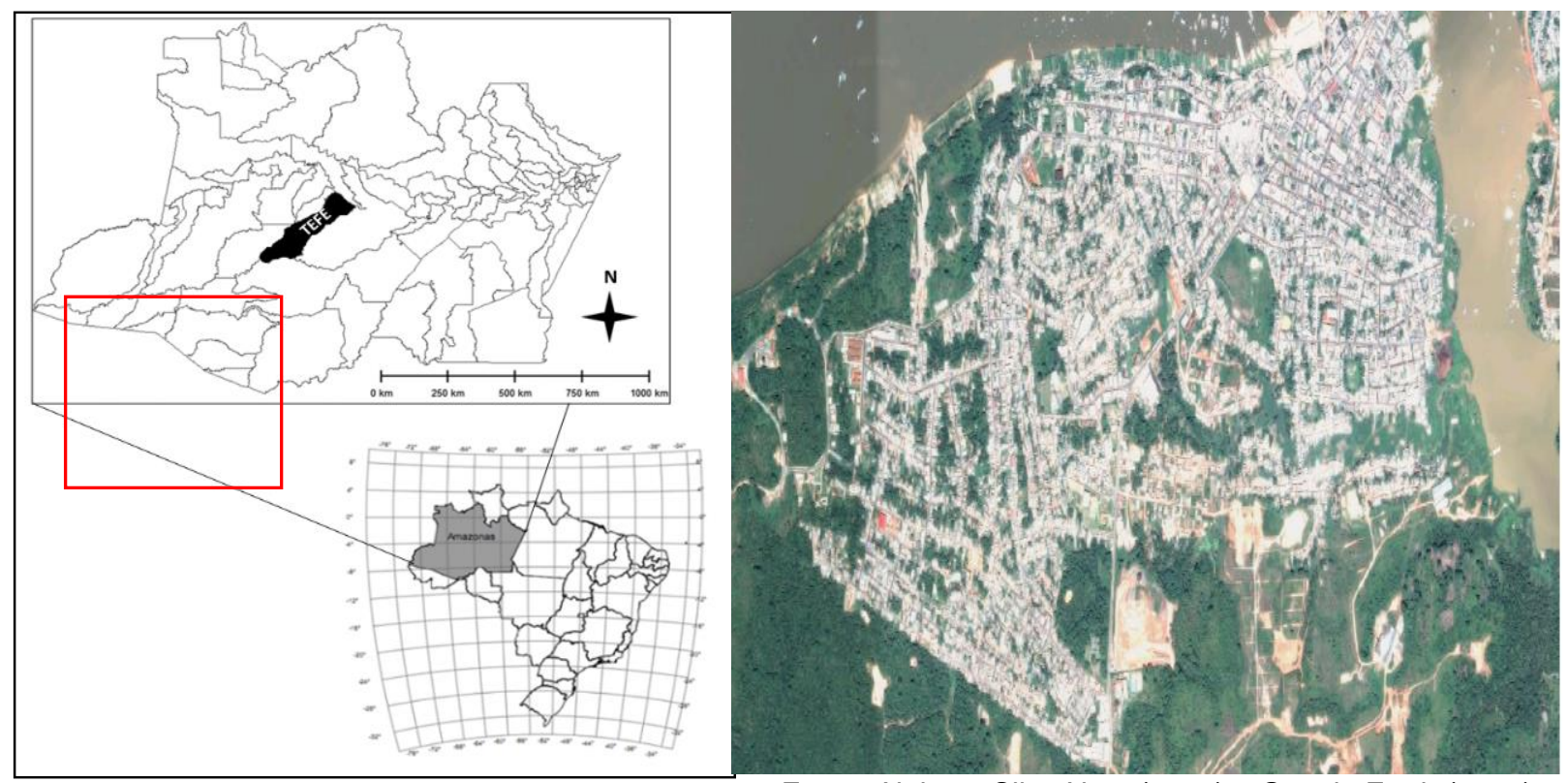

Fonte: Aleixo e Silva Neto (2015) e Google Earth (2016).

Figura 1. A) Mapa do estado do Amazonas, em destaque o município de Tefé. B) Imagem de satélite do município de Tefé-Amazonas, em destaque o bairro Fonte Boa

Figure 1. A) Amazonas state map in highlight Tefé municipal district. B) Satellite image of Tefé district Amazonas, highlight neighborhood Fonte Boa

\section{Metodologia}

Utilizou-se questionários semiestruturados contendo 19 questões objetivas e abertas distribuídas em três tópicos: (I - Localização e identificação) averiguadas inicialmente pelo entrevistador para caracterizar visualmente as condições climáticas e ambientais e (II - Perfil dos entrevistados e III - Opinião dos entrevistados) realizou-se pelo método de entrevista (Figura 3). Inicialmente foi realizada a contagem das casas somente do lado direito de cada rua, independente do lado que se adentrava, em seguida realizou-se o sorteio através do programa Microsoft Excel $2013^{\circledR}$, o qual definiu 10 casas divididas de forma equitativa para cada lado da rua.

As entrevistas foram realizadas entre os meses de fevereiro e março do ano de 2016 em $100 \%$ das ruas do referido bairro (12 ruas) sempre no período da manhã, totalizando 120 entrevistas, representando uma amostragem aleatória significativa de $3,75 \%$ do total de habitantes. O critério de escolha do participante foi ter idade igual ou superior a 18 anos e somente um participante por residência. Todos os entrevistados assinaram o Termo de Consentimento Livre Esclarecido (TCLE), autorizando a divulgação dos resultados.

Os dados foram tabulados, processados e analisados por meio do Microsoft Excel $2013^{\circledR}$. Os resultados foram apresentados em tabelas na forma de números absolutos e percentagem. 


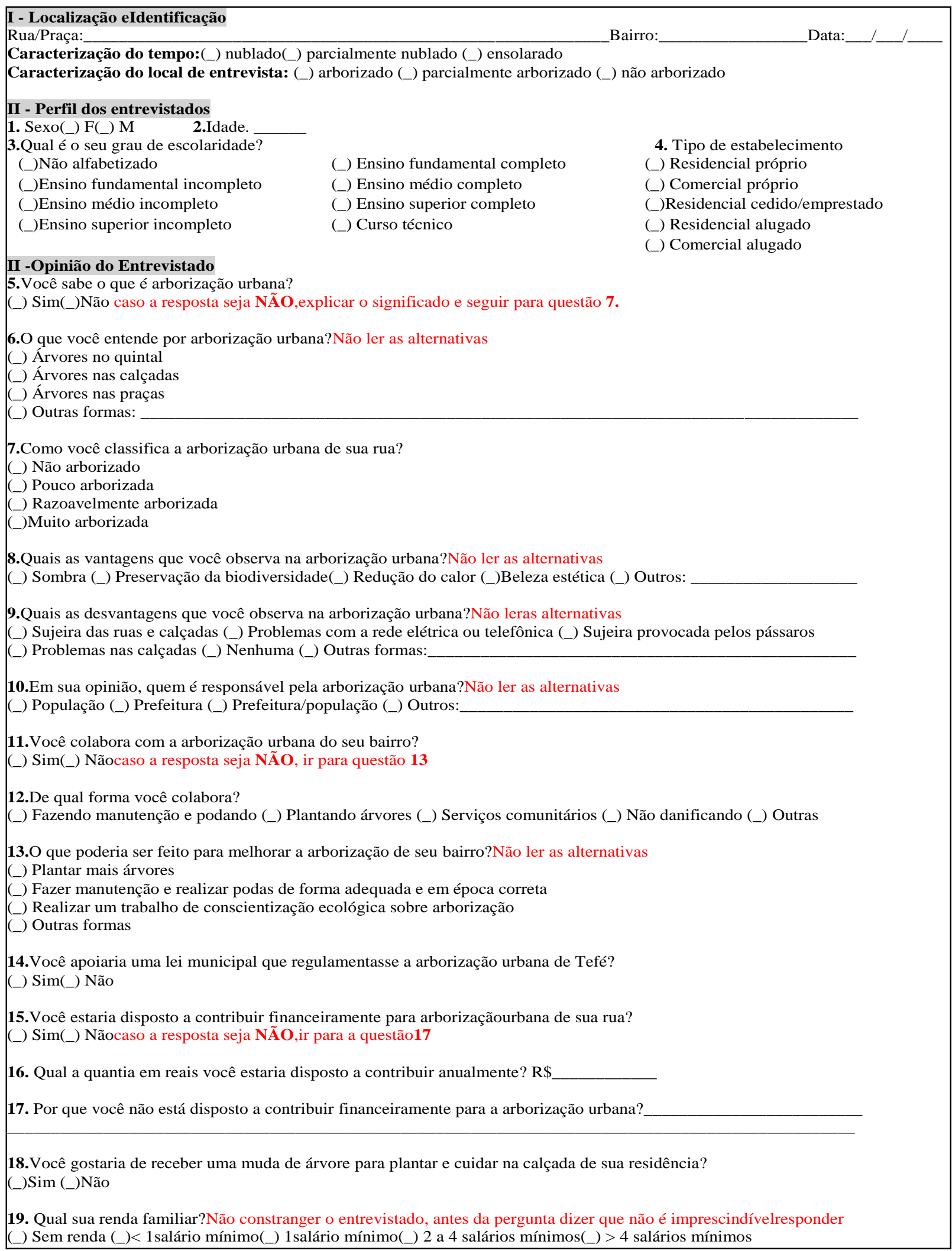

Figura 3. Questionário utilizado nas entrevistas com os moradores do bairro Fonte Boa em Tefé-AM Figure 3. Questionnaire used in the interviews with the inhabitants of Fonte Boa neighborhood in Tefé-AM 


\section{RESULTADOS E DISCUSSÃO}

Realizou-se a caracterização do tempo nos dias das entrevistas, no qual $66,7 \%$ das entrevistas foram realizadas em dias parcialmente nublado, $25 \%$ em dias ensolarados e $8,3 \%$ em dias nublados (Tabela 1). No entanto, mesmo com a maior parte das entrevistas sendo realizada em dias parcialmente nublados, a maioria dos entrevistados observaram a sombra como vantagem da arborização, seguida de redução da temperatura. Ressalta-se que o município apresenta altas temperaturas durante o ano, desta forma, é notório que a população observa principalmente os benefícios relacionados a melhoria no clima.

$\mathrm{Na}$ caracterização do local pelo entrevistador, 83,3\% das entrevistas foram realizadas em lugares parcialmente arborizados e 16,7\% em local não arborizado. $\mathrm{Na}$ opinião dos entrevistados, $62,5 \%$ classificaram sua rua como pouco ou razoavelmente arborizada. Estes resultados demonstram que a população está insatisfeita com a insuficiência de árvores no município. Vale lembrar que nenhuma entrevista foi realizada em local muito arborizado, porém, observa-se que $30,8 \%$ classificaram a rua como muito arborizada, resultados estes que podem ser explicados em decorrência do morador observar somente as árvores existentes próximo ou em frente a sua residência.

Tabela 1. Caracterização do tempo e local das entrevistas observadas pelo entrevistador e entrevistados no bairro Fonte Boa em Tefé-AM

Table 1. Characterization of time and location of interviews observed by interviewers and respondents in Fonte Boa neighborhood in Tefé-AM

\begin{tabular}{lcc}
\hline Variável & N & $\%$ \\
\hline Caracterização do Tempo pelo entrevistador & & \\
\hline Parcialmente nublado & 80 & 66,7 \\
Ensolarado & 30 & 25 \\
Nublado & 10 & 8,3 \\
\hline Caracterização do local de entrevista pelo entrevistador & & \\
\hline Parcialmente arborizado & 100 & 83,3 \\
Não arborizado & 20 & 16,7 \\
Arborizado & 0 & 0 \\
\hline Caracterização do local de entrevista pelos entrevistados & \multicolumn{2}{c}{} \\
\hline Pouco arborizado & 58 & 48,3 \\
Muito arborizado & 37 & 30,8 \\
Razoavelmente arborizado & 17 & 14,2 \\
Não arborizado & 8 & 6,7 \\
\hline
\end{tabular}


Dos 120 entrevistados, 63\% eram do sexo feminino, estes resultados podem estar relacionados devido o fato de as entrevistas terem sido realizadas sempre no período da manhã. A idade média foi de 36,29 anos $( \pm 15,78)$ com a mínima de 18 e a máxima 78 anos. Em relação a faixa etária $47 \%$ possuem menos de 30 anos, destes, 28\% tinham idades entre 18 a 24 anos seguido de mais que 50 anos com $20 \%$.

Em relação à escolaridade $36 \%$ dos entrevistados possuíam até 8 anos de estudos, $47,5 \%$ tinham até 12 anos, 15\% estudaram mais que 12 anos e $8 \%$ não frequentaram a escola. Referente a renda dos entrevistados, $46 \%$ ganha 1 salário mínimo, seguido de 2 a 4 salários mínimos, que correspondem a 40\% (Tabela 2).

Tabela 2. Perfil social dos entrevistados no bairro Fonte Boa no município de Tefé-AM Table 2. Social Profile of people interviewed in Fonte Boa neighborhood, Tefé-AM

\begin{tabular}{lll}
\hline Variável & $\mathbf{N}$ & $\%$ \\
\hline Gênero & & \\
\hline Feminino & 75 & 63 \\
Masculino & 45 & 38 \\
\hline Faixa etária & & \\
\hline 18 a 24 & 34 & 28 \\
25 a 30 & 23 & 19 \\
31 a 39 & 20 & 17 \\
40 a 50 & 19 & 16 \\
Mais que 50 & 24 & 20 \\
\hline Escolaridade & & \\
\hline Não alfabetizado & 9 & 7,5 \\
Ensino Fundamental Incompleto & 34 & 28,3 \\
Ensino Fundamental Completo & 2 & 1,7 \\
Ensino Médio Incompleto & 16 & 13,3 \\
Ensino Médio Completo & 41 & 34,2 \\
Curso Técnico & 1 & 0,8 \\
Ensino Superior Incompleto & 9 & 7,5 \\
Ensino Superior Completo & 8 & 6,7 \\
\hline Renda Mensal & & \\
\hline Menor que 1 Salário Mínimo & 11 & 10 \\
1 Salário Mínimo & 52 & 46 \\
2 a 4 Salários Mínimos & 46 & 40 \\
Mais que 4 Salários Mínimos & 5 & 4 \\
Preferiu não responder & 4 & 3 \\
Não possui renda própria & 2 & 1,7 \\
\hline
\end{tabular}

Quando questionado sobre o conhecimento do conceito "arborização urbana" 77,5\% disseram não saber. Entre os entrevistados que responderam que sabiam, 82,8\% creem que são árvores na cidade, 6,9\% disseram ser árvores nas calçadas, seguido de árvores no quintal com $6,9 \%$ e $3,4 \%$ responderam árvores nas ruas. O grau de escolaridade e a renda dos moradores 
podem estar relacionados no nível de percepção em relação à arborização e também em decorrências da falta de informações.

No quesito sobre as vantagens da arborização a maioria dos entrevistados citou a sombra com 42,1\%, seguido de redução do calor com 17,9\% das respostas (Figura 4). Crosara (2013), em sua pesquisa na cidade de Uberlândia-MG, encontrou resultados semelhantes, nos quais $27 \%$ dos entrevistados citaram a sombra como vantagem. Esses resultados podem ser explicados devido à falta de conhecimento da população a respeito da arborização, tendo em vista seus vários benefícios, e pelo o fato de o município apresentar altas temperaturas, principalmente no verão. Desta forma, a população observa principalmente os benefícios relacionados à melhoria do clima.

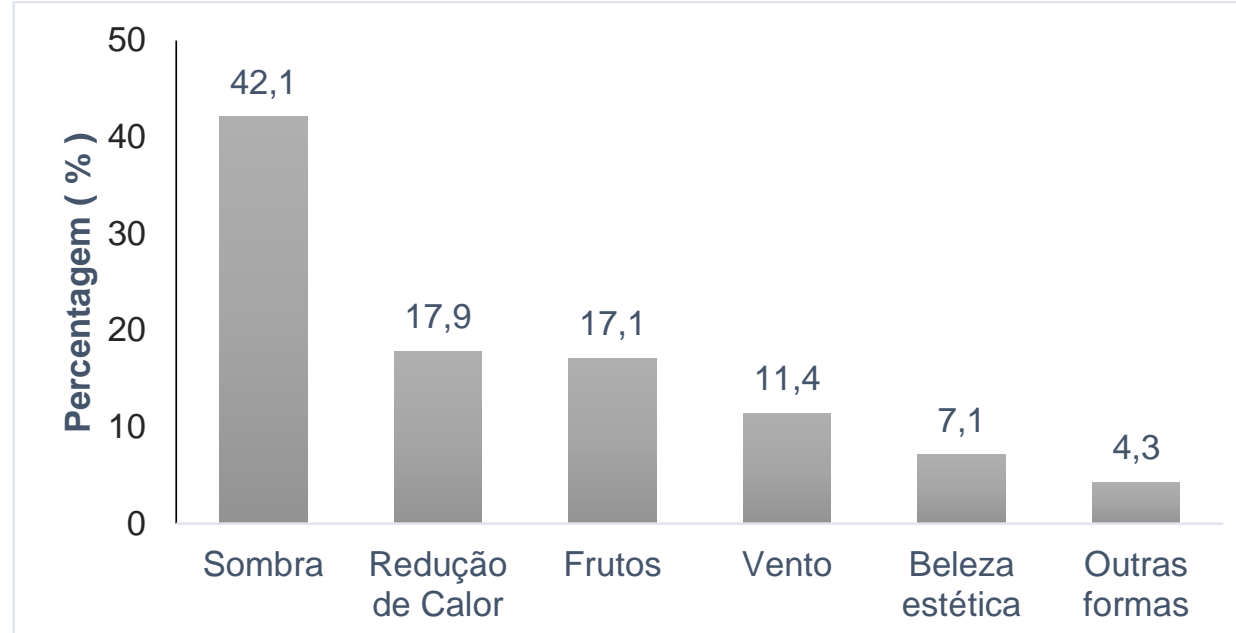

Figura 4. Frequência de respostas sobre as vantagens da arborização urbana observada pelos entrevistados no bairro Fonte Boa em Tefé-AM

Figure 4. Answers' frequency on the advantages of the urban tree planting by the respondents in Fonte Boa neighborhood, Tefé-AM

No que se refere as desvantagens da arborização, 59,5\% dos entrevistados notam pontos negativos, enquanto 40,1\% disseram não observar nenhuma desvantagem (Figura 5). Diversos autores obtiveram dados que se diferem a este (SANTANA; OLIVEIRA, 2012; CANSIAN; ANGELIS, 2012; RODRIGUES et al., 2010; PIZZIOLO et al., 2014). Contudo, mesmo com o pouco convívio com a arborização, a maior parte dos entrevistados observa algumas desvantagens. Diante destes fatos, é essencial a elaboração de projetos de educação ambiental, visando mostrar os benefícios da arborização para o bem estar da sociedade, sobrepondo-se, desta forma, diante das desvantagens.

Quando inquiridos sobre quem é o responsável pela arborização urbana, 51,7\% dos participantes afirmaram ser a população. Lacerda et al. (2010), encontraram resultados semelhantes em seu estudo na cidade de São José de Piranhas - PB, no qual, 46,4\% dos entrevistados atribuíram a responsabilidade aos próprios moradores. 


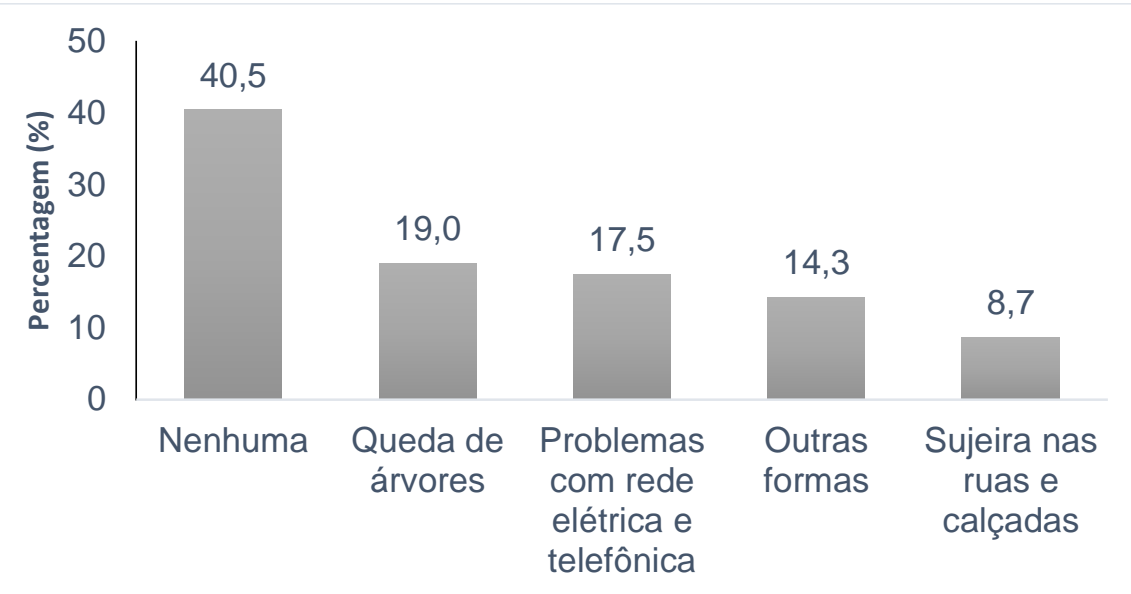

Figura 5. Frequência de respostas em relação às desvantagens da arborização urbana observada pelos moradores do bairro Fonte Boa em Tefé-AM

Figure 5. Answers' frequency in relation to the disadvantages of the urban tree planting by the respondents in Fonte Boa neighborhood, Tefé-AM

Em decorrência da falta de conhecimento acerca da responsabilidade da arborização, os moradores acreditam que cada um é responsável pelas árvores que plantam ou pelas existentes em frente a sua residência. No entanto, o novo Código Florestal, lei №. 12.651 de 25 de Maio de 2012, ressalta que é dever da União, Estados, Distrito Federal e Municípios em conjunto com a sociedade civil a proteção e preservação da arborização urbana (BRASIL, 2016).

O fato de a população atribuir aos próprios moradores a responsabilidade da arborização urbana pode gerar diversos entraves para sociedade, tais como: plantio de árvores em lugares não apropriados ocasionando conflito com as calçadas e também a rede elétrica, podas irregulares que podem acarretar em diversos problemas fitossanitários, podendo até levar a queda do vegetal. Desta forma, é imprescindível que o governo municipal obtenha conhecimento dos assuntos referentes a esta temática, bem como, atue na elaboração do plano de arborização urbana no município.

Dentre as formas de colaboração da população para a arborização urbana, $56 \%$ dos moradores responderam que não colaboram. Dos que disseram que sim, 63,0\% alegaram cooperar no plantio de árvores, 22,2\% afirmaram que executam a manutenção e poda, 9,3\% citaram não danificando e 5,6\% realizam serviços comunitários. Segundo Coletto, Müller e Wolski (2008), o plantio de árvores no espaço urbano deve ser desenvolvido a partir do planejamento levando em conta a situação de cada localidade, bem como a seleção das espécies a serem utilizadas. Diante disso, é essencial que governo municipal atue no planejamento de espaços destinados a esta atividade. Roppa et al. (2007), na sua pesquisa em Santa Maria - RS, encontrou dados diferente, que indicaram que $81,5 \%$ dos entrevistados colaboram com a arborização, e destes $64,6 \%$ responderam não danificando as árvores. É fundamental destacar 
que, a arborização urbana é um patrimônio ambiental inestimável, sendo previsto em leis e decretos que é dever de todos a sua proteção e preservação.

Quando perguntado aos participantes sobre o que poderia ser feito para melhorar a arborização do seu bairro, 46,2\% responderam que deveria ser plantado mais árvores e 20,6\% responderam que deveria ser executada manutenção e podas de forma adequada e em época correta, 19,0\% citaram outras formas e 11,1\% acreditam que deve ser realizado um trabalho de conscientização sobre a importância da arborização urbana (Figura 6). Cansian e Angelis (2012), em seu estudo na cidade de Maringá-PR, observaram dados semelhantes, no qual 46,2\% dos entrevistados acreditam que para a melhora da arborização, deve-se realizar plantio de mais árvores.

Para Aqua e Müller (2014), a arborização urbana não consiste em apenas plantar árvores na cidade, é necessário realizar um estudo e conhecer as peculiaridades de cada localidade. Desta forma, para que a arborização urbana prospere é necessário realizar planejamento da implantação da mesma juntamente com um trabalho de educação ambiental com o objetivo de mostrar a população à importância da arborização no espaço urbano. É essencial que a governo municipal trabalhe em parceria com os moradores.

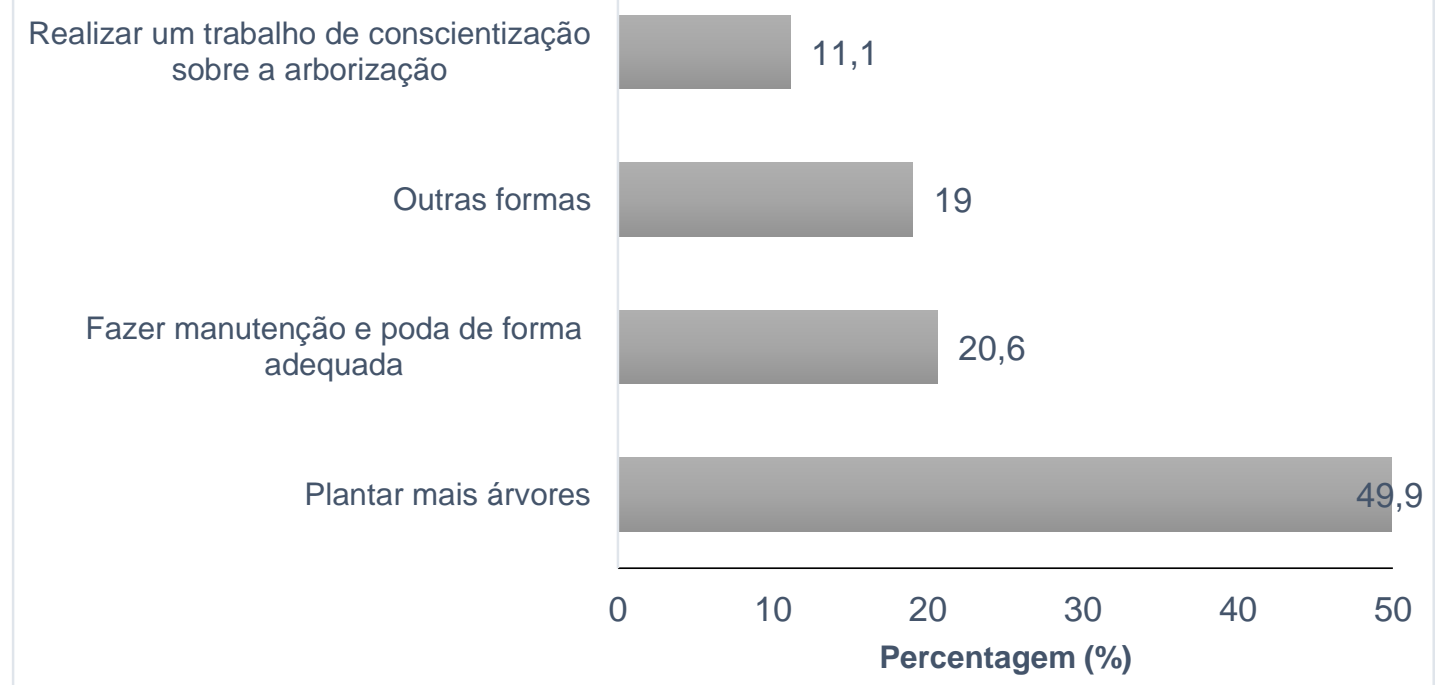

Figura 6. Frequência de respostas sobre a opinião dos entrevistados em relação ao que poderia ser feito para melhorar a arborização local

Figure 6. Answers' frequency on innhabitants opinion in relation to what could be done to improve the local tree planting

$\mathrm{Na}$ questão referente a opinião à respeito de uma lei que regulamente a arborização urbana em Tefé, 93\% dos moradores afirmou ser a favor. Na pesquisa de Araújo et al. (2010), na cidade de Campina Grande-PB, resultados distintos foram encontrados revelando que 50\% dos entrevistados é a favor da lei. Esses dados demonstram que a população se mostra favorável as questões em relação a implantação da arborização no município. Sendo assim, é de grande 
importância que governo municipal elabore programas de educação ambiental e plano de implantação da arborização no município, tendo em vista que a população demonstra ter interesse quanto a arborização.

Referente à contribuição financeira dos entrevistados para a arborização, 87\% disseram estarem dispostos a cooperar. O valor mais citado foi $\mathrm{R} \$ 10$ anuais com $32,7 \%$ (Figura 7 ). $\mathrm{Na}$ pesquisa de Lacerda et al. (2010), na cidade de São José de Piranhas - PB, dados distintos a estes foram observados, no qual $83,5 \%$ dos participantes disseram que não contribuiriam financeiramente.

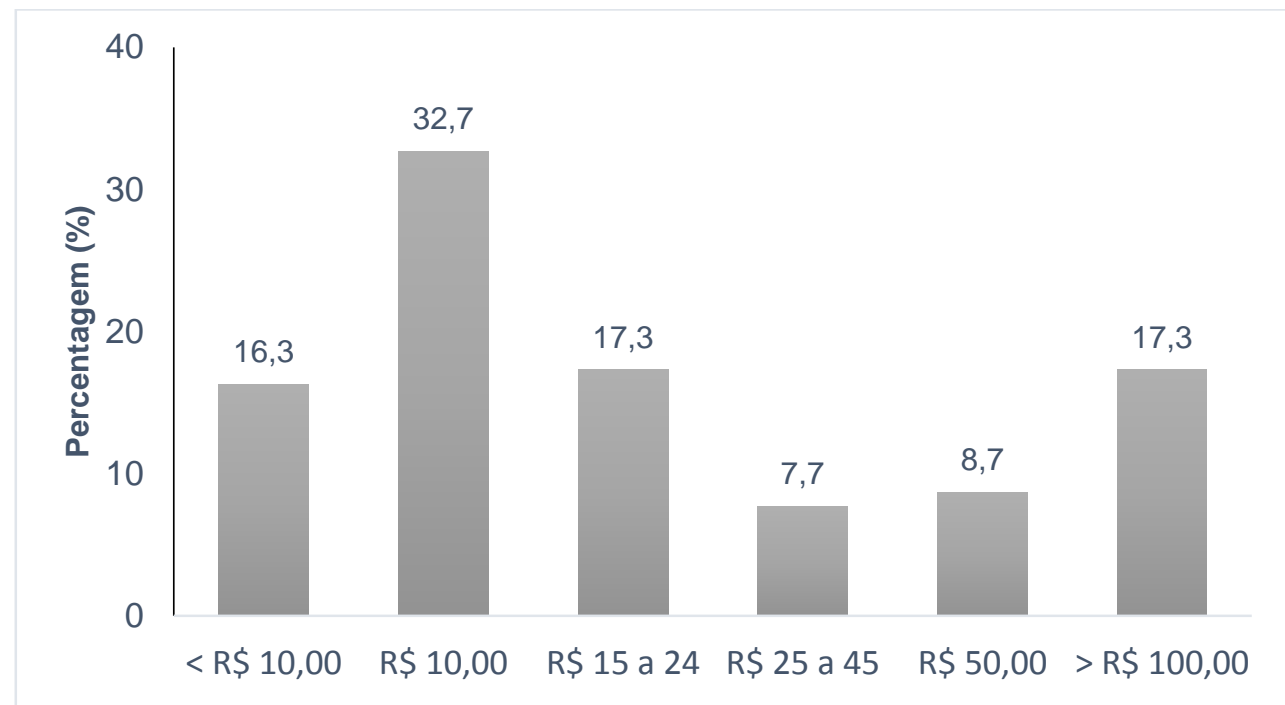

Figura 7. Valor citado pelos entrevistados sobre a questão de contribuição financeira anual para arborização urbana

Figure 7. Value cited by the respondents about the annual financial contribution for urban tree planting

Em relação aos $13 \%$ que disseram não estar dispostos a contribuir financeiramente para a arborização, 43,8\% relataram não possuir renda e 18,8\% responderam que é dever da prefeitura (Figura 8). É notório que os benefícios da arborização são difíceis de atribuir valor financeiro, desta forma, pequenas contribuições podem se tornar insignificantes diante da sua importância, sendo imprescindível que cada um faça sua parte (ROPPA et al., 2007).

Quando interrogados se gostariam de receber uma muda de árvore para plantar na calçada de sua residência, $78 \%$ responderam que sim. Dentre os entrevistados que expuseram que não gostariam de receber uma muda de árvore, a maioria relatou que não possui espaço adequado para o plantio devido à falta de planejamento do crescimento da cidade e, consequentemente, da implantação da arborização urbana no município. 


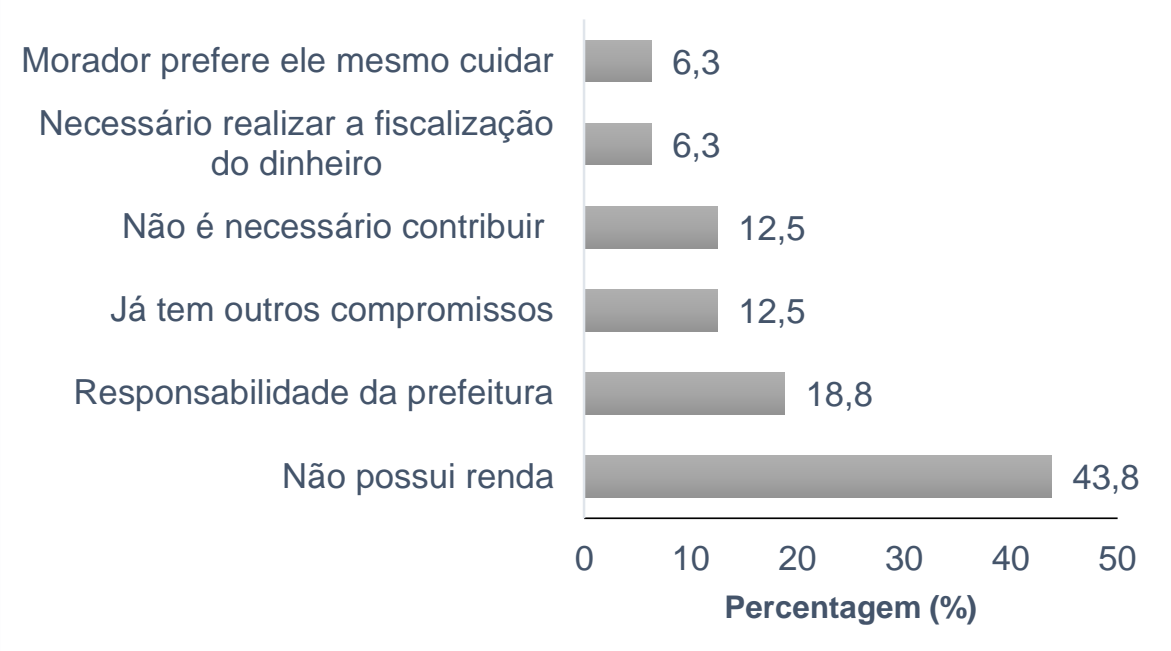

Figura 8. Motivos pelos quais os moradores não contribuiriam financeiramente para a arborização Figure 8. Reasons by the which are the inhabitants would not contribute for the urban tree planting

É perceptivo que população mostra-se com interesse quanto às questões da arborização. Cabe ao governo municipal planejar novos espaços e empreendimentos destinados a esta atividade. Sendo assim, é essencial que as administrações públicas elaborem o plano de arborização urbana, incluindo ações de educação ambiental visando levar conhecimentos sobre o tema à população.

\section{CONCLUSÕES}

Os resultados obtidos indicaram que a maioria dos entrevistados não tem conhecimento sobre o conceito "arborização urbana". No entanto, quando esclarecido sobre o que se refere, os moradores reconhecem as vantagens e os pontos negativos da mesma, com destaque para os benefícios relacionados a sombra.

Assim sendo, pode-se observar a necessidade de a administração pública elaborar e executar o plano de arborização urbana. Outro fato pertinente é elaboração de oficinas e projetos de educação ambiental, visando levar conhecimento aos moradores a respeito do conceito de arborização urbana e sua importância na qualidade de vida da população. Desta forma, para que seus benefícios se destaquem em relação as desvantagens é indispensável que a administração municipal realize projetos de forma participativa, para que população sinta-se atuante nas atividades e responsável pelo desenvolvimento da arborização urbana no município. 


\section{REFERÊNCIAS}

ALEIXO, N. C. R.; SILVA NETO, J. C. A. da. Precipitação e riscos em Tefé-AM. Revista GeoUECE, Fortaleza, v.08, n.04, p.1176-1190, 2015.

AQUA, M. D.; MÜLLER, N. T. G. Diagnóstico da Arborização Urbana de duas ruas na cidade de Santa Rosa - RS. Revista da Sociedade Brasileira de Arborização Urbana, Piracicaba, v. 9, n. 3 , p. $141-155,2014$.

ARAÚJO, J. de L. O.; ARAÚJO, A. C. de; ARAÚJO, A. C. de. Percepção ambiental dos residentes do bairro Presidente Médici em Campina Grande - PB, no tocante à arborização local. Revista da Sociedade Brasileira de Arborização Urbana, Piracicaba, v. 5, n. 2, p. 67-81, 2010.

BRASIL. Lei no 12.651 de 2012. O novo código florestal. Disponível em: <http://www.planalto.gov.br/ccivil_03/_ato2011-2014/2012/lei//12651.htm> Acesso em: 20 abril 2016.

CANSIAN, D. C. V.; ANGELIS, B. L. D. de. Educação ambiental como ferramenta para a conscientização sobre arborização urbana: Seminário de Pós-Graduação em Engenharia Urbana, 3., Maringá. Anais... Maringá: SIMPGEU, 2012. p. 1 - 9.

COLETTO, E. P.; MÜLLER, N. G.; WOLSKI, S. S. Diagnóstico da arborização das vias públicas do município de Sete de Setembro - RS. Revista da Sociedade Brasileira de Arborização Urbana, Piracicaba, v. 3, n. 2, p. 110-122, 2008.

COSTA, C. G. F.; BEZERRA, R. F.; FREIRE, G. S. S. Avaliação da percepção da arborização urbana em Fortaleza. Revista da Sociedade Brasileira de Arborização Urbana, Piracicaba, v. 8, n. 4, p. 73-88, 2013.

COSTA, R. G. S.; COLESANTI, M. M. A contribuição da percepção ambiental nos estudos das áreas verdes. RA'E GA, Curitiba, v. 22, n. 2, p. 238-251, 2011.

CROSARA, R. A percepção da população do bairro Jardim Umuarama sobre a importância de sua arborização. Geosaberes, Fortaleza, v. 4, n. 7, p. 16-32, 2013.

FARIA, J. L. G.; MONTEIRO, E. A.; FISCH, S. T. V. Arborização de vias públicas do município de Jacareí - SP. Revista da Sociedade Brasileira de Arborização Urbana, Piracicaba, v. 2, n. 4, p. 20-33, 2007.

GOIS, D. V.; FIGUEIREDO, M. L. F. G.; BARBOSA, E.; MELO e SOUZA, R. O processo de apropriação da natureza no espaço urbano em cidades tropicais: problematizando a distribuição de áreas verdes em Aracaju (SE). Natural Resources, Aquidabã, v.2, n.1, p.44-67, 2012.

INSTITUTO BRASILEIRO DE GEOGRAFIA E ESTATÍSTICA (IBGE). Censo Demográfico 2010. Disponível em: <http://www.cidades.ibge.gov.br> Acesso em: 6 abril 2016.

LACERDA, P. N.; SOUTO, P. C.; DIAS, R. S.; SOUTO, L. S.; SOUTO, J. S. Percepção dos residentes sobre a arborização da cidade de São José de Piranhas - PB. Revista da Sociedade Brasileira de Arborização Urbana, Piracicaba, v. 5, n. 4, p. 81-95, 2010.

PAGLIARI, S. C.; DORIGON, E. B. Arborização urbana: Importância das espécies adequadas. Unoesc \& Ciência - ACET, Joaçaba, v. 4, n. 2, p. 139-148, 2013. 
PERIOTTO, F.; PITUCO, M. M.; HELMANN, A. C.; SANTOS, T. O. dos.; BORTOLOTTI, S. L. Análise da Arborização Urbana no município de Medianeira, Paraná. Revista da Sociedade Brasileira de Arborização Urbana, Piracicaba - SP, v.11, n.2, p. 59-74, 2016.

PIZZIOLO, B. V.; TOSTES, R.; SILVA, K.; ARRUDA, V. M. Arborização urbana: Percepção ambiental dos moradores dos bairros Bom Pastor e Centro da cidade de Ubá/MG. Revista Eletrônica em Gestão, Educação e Tecnologia Ambiental, Santa Maria, v. 18, n. 3, p. 11621169, 2014.

PORTO, K. de S. Impactos socioambientais do processo de ocupação da orla do município de Tefé/Amazonas - O Bairro Juruá. São Paulo, 2011. 110f. Dissertação (Mestrado em Geografia Humana) - Faculdade Filosofia, Letras e Ciências Humanas, São Paulo, 2011.

QUADROS, L. S.; FREIRE, F. Percepção ambiental dos residentes da cidade de Assis - SP com relação à arborização viária da Avenida Rui Barbosa. Revista da Sociedade Brasileira de Arborização Urbana, Piracicaba - SP, v.4, n.2, p.16-34, 2009.

RODRIGUES, T. D.; MALAFAIA, G.; QUEIROZ, S. E. E.; RODRIGUES, A. S. de L. Percepção sobre arborização urbana de moradores em três áreas de Pires do Rio - Goiás. Revista de Estudos Ambientais, Blumenau, v. 12, n. 2, p. 47-61, 2010.

ROPPA, C.; FALKENBERG, J. R.; STANGERLIN, D. M.; BRUN, F. G. K.; BRUN, E. J.; LONGHI, S. J. Diagnóstico da percepção dos moradores sobre a arborização urbana na vila Estação Colônia - bairro Camobi, Santa Maria - RS. Revista da Sociedade Brasileira de Arborização Urbana, Piracicaba, v. 2, n. 2, p.11-30, 2007.

SANTANA, F. A.; OLIVEIRA, S. M. S. Arborização urbana: Avaliação de moradores de cinco Bairros de Santarém- Pará. Perspectiva Amazônica - Santarém - PA. Ano II. Vol. 4 p.18-26 Ago. 2012.

SILVA NETO, J. C. A. da.; ALEIXO, N. C. R. Apropriação da natureza e processos erosivos na região do médio Solimões - AM. GeoUECE, Fortaleza, v. 3, n. 4, p. 151-176, 2014.

VIANA, A. L.; LOPES, M. C.; NETO, N. F. de A. L.; KUDO, S. A.; GUIMARÃES, D. F. da S.; MARI, M. L. G. Análise da percepção ambiental sobre os parques urbanos da cidade de Manaus, Amazonas. Revista Monografias Ambientais, v. 13, n. 5, p. 4044-4062, 2014.

VILLAR, L. M.; ALMEIDA, A. J. de; LIMA, C. A. de; ALMEIDA, J. L. de; SOUZA, L. F. B de; PAULA, V. S. de. A percepção ambiental entre os habitantes da região noroeste do estado do Rio de Janeiro. Esc. Anna Nery Rev Enferm, Rio de Janeiro, v. 12, n. 2, p. 285-290, 2008.

WALDMAN, M.. Crise Ambiental: Ponderando a Respeito de um Dilema da Modernidade. Revista Crítica Histórica, Alagoas, v. 2, n. 4, p. 225-313, 2011. 